\title{
Kegels Exercises: A crucial issue during woman's lifespan
}

\author{
Hanan Elzeblawy Hassan
}

Maternal and Newborn Health Nursing, Faculty of Nursing, Beni-Suef University, Egypt, nona_nano_1712@yahoo.com

\begin{abstract}
Urinary incontinence and pelvic organ prolapse are common bothersome among women. There are lots of treatments to manage these diseases, including medication and surgeries. Clinicians consider Kegel exercises, designed for pelvic floor muscle strengthening, as the first-line therapy for patients as there are few reported few side effects. In the general population, age 15 to 64 years, 10\%-30\% of women are affected. Those with overactive bladder $(O A B)$, the bladder muscle contracts spastically, sometimes without a known cause, resulting in elevated bladder pressure and the urgent need to urinate. Of the several types of urinary incontinence, stress, urge, and mixed incontinence account for more than 90\% of the cases. Kegel exercises target the pelvic floor muscles, helping to strengthen the urethra, bladder, uterus, and rectum. Pelvic floor muscle exercises also help strengthen vaginal muscles, improve flexibility, strength, and motor control, facilitating the second stage of labor and reducing the need for instrumented delivery. Pregnant women are encouraged to do Kegel exercises because strong pelvic floor muscles help make childbirth, specifically pushing, easier. In addition, the exercise can lower the incidence of tears during the intra-partum \& postpartum periods. Doing Kegel exercises can help in healing from an episiotomy as well as prevent postpartum incontinence and tone stretched out vaginal muscles, thereby making sex better. Nurse in the perinatal setting plays a crucial role in educating the mother about Kegel exercises. This minireview was conducted to educated \& training women on how to perform Kegel exercises to reduce prone to labor injury, incontinence, and prolapse.
\end{abstract}

Keywords: Kegels Exercises, women, stress incontinence, prolapse, episiotomy.

\section{Introduction}

Kegels are exercises done to strengthen your pelvic floor muscles (the muscles that support your urethra, bladder, uterus, and rectum). Kegel exercises were first described by a gynecologist Arnold Kegel, who recommended them back in the 1940s, for pelvic floor muscle strengthening and to help women with urinary incontinence, or diminished bladder control, which can happen after childbirth. Dr. Kegel's studies showed that the exercises will help to prevent women's urinary stress incontinence (USI), cystocele, and rectocele. AshtonMiller et al. indicated that urethral sphincters and supportive systems in females could prevent urinary incontinence and genital organ prolapse. To maximize the benefits of Kegel exercises, the woman should exercise the right muscles with sufficient time for training. However, about $30 \%$ of women could not contract the pelvic floor muscles correctly. According to the results of another study; $46.1 \%$ of women did not receive the information about Kegel exercises.

\section{Benefits of Kegel Exercises}

International Continence Society (ICS) is defined as urinary incontinence as the complaint of any involuntary leakage of urine. According to existing literature; the prevalence of urinary incontinence is ranged from $25 \%-45 \%$ among women, with a higher prevalence among the elder ones. More than
$40 \%$ of women aged 70 years and older were affected by urinary incontinence based according to the study conducted by Milsom et al. Kegel exercises are considered the first-line therapy for patients with urinary incontinence as there are few reported side effects. According to the study of Cavkaytar et al., the patients awaiting anti-incontinence surgery showed statistically lower scores in IIQ-7 and UDI-6 after doing Kegel exercises.

Women who perform Kegel exercises often find they have an easier birth. Strengthening these muscles during pregnancy can help pregnant women to develop the ability to control the muscles during labor and delivery. Toning all of these muscles will also minimize two common problems during pregnancy: bladder control and hemorrhoids.

Kegel exercises are also recommended after pregnancy to promote perineal healing, regain bladder control, and strengthen pelvic floor muscles. The best thing about Kegel exercises is that they can be done anywhere and no one knows you're doing them.

Because that Kegels improve circulation to the rectal and vaginal area, they may help keep hemorrhoids at bay and possibly speed healing after an episiotomy or tear during childbirth. Finally, continuing to do Kegel exercises regularly 
after giving birth not only helps to maintain bladder control, it also improves the muscle tone of the vagina, making sex more enjoyable.

\section{How to Do Kegel Exercises}

Currently, there is no fixed protocol for Kegel exercises, but the critical point is that the patients should contract the pelvic floor muscle rather than abdominal, buttock, or inner thigh muscles. Women usually don't have sufficient knowledge about general pregnancy topics and pelvic floor risks. Thus, it is essential to give them adequate information and instruction. Furthermore, to achieve better outcomes, the patients are recommended to perform Kegel exercises regularly under the supervision of specialists.

Incorporating Kegel exercises into your everyday routine can help ward off pelvic floor problems, including urinary incontinence, and is beneficial for women who have difficulty achieving orgasm. Many things can lead to weakened pelvic muscles, but Kegel performed regularly can strengthen the pelvic muscles. It takes some effort and time to learn how to do Kegel properly, but it is worth the effort.

\section{Steps Kegel Exercises}

\section{Find your pelvic muscles.}

- While urinating, try to stop the flow. This tightening is the basic move of a Kegel. However, don't use this as your regular Kegel exercise routine. Doing Kegel while urinating can actually have the opposite effect, weakening the muscle.

- $\quad$ Place your finger in your vagina and squeeze your muscles. You should feel the muscles tightening and your pelvic floor move up. Relax and you'll feel the pelvic floor move back again.

\section{Tighten and relax these muscles daily.}

- $\quad$ Try and work up to $100-200$ times a day.

- You can choose a certain thing to associate with them - for instance, kegel at every red light you come to, or every time you open the fridge.

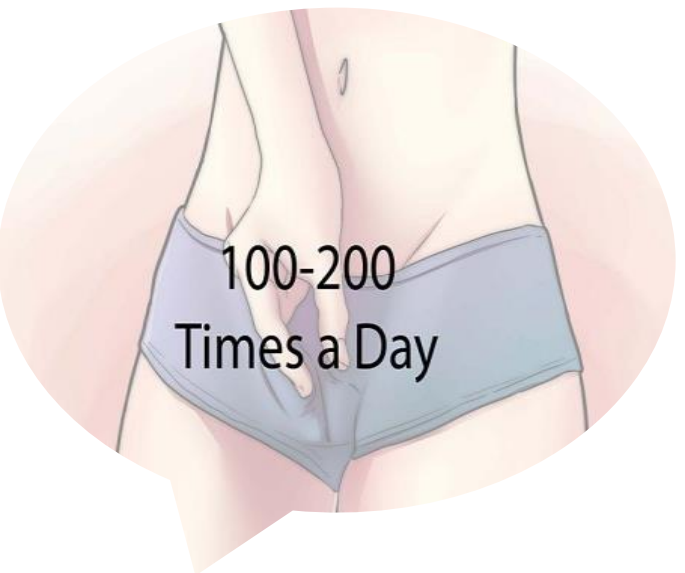

\section{Get into a comfortable position.}

- You can do these exercises either sitting in a chair or lying on the floor.

- Make sure your buttock and tummy muscles are relaxed.

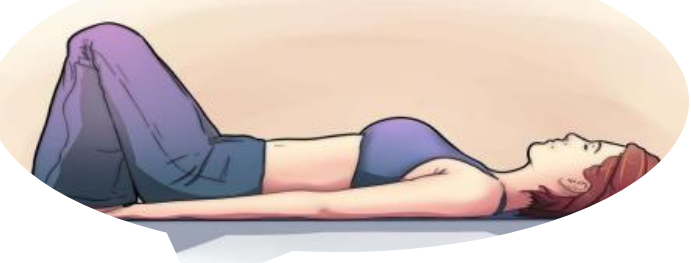

\section{Concentrate only on the pelvic floor muscles}

- Try not to tighten any other area of your body.

- $\quad$ Breathe normally during the exercise.

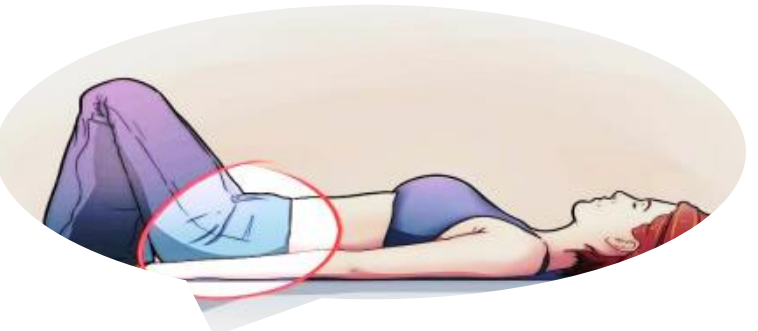

\section{To do a quick kegel:}

- Quickly squeeze the pelvic floor muscles and release 10 times in a row.

- This should only take about 10 seconds.

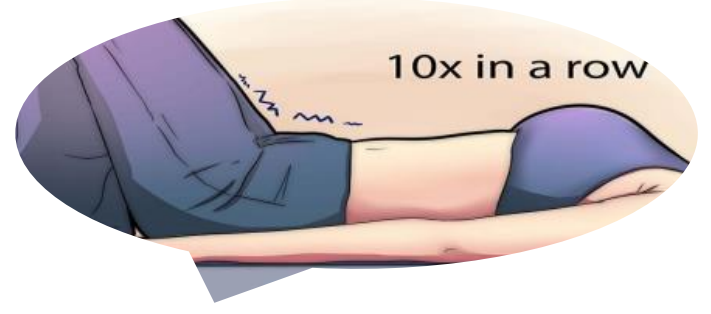

6. To do a slow kegel:

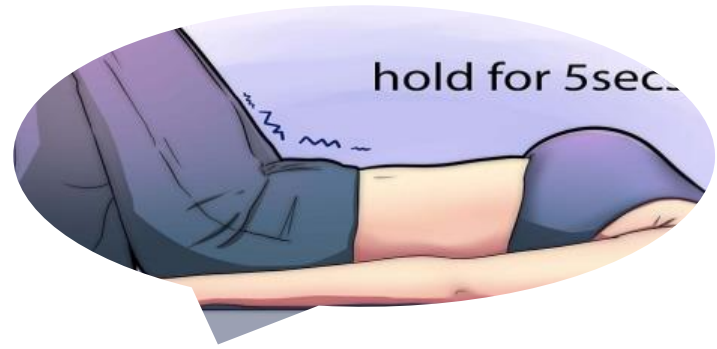


- $\quad$ Squeeze the pelvic floor muscles for 5 seconds and release.

- Do this 10 times. It should take about 50 seconds to complete a slow kegel.

\section{To perform a pull-in kegel:}

- Think of your pelvic floor muscles as a vacuum.

- $\quad$ Tense your butt and pull your legs up and in. Hold this position for 5 seconds and then release it.

- Do this 10 times in a row. It should take about 50 seconds to complete.

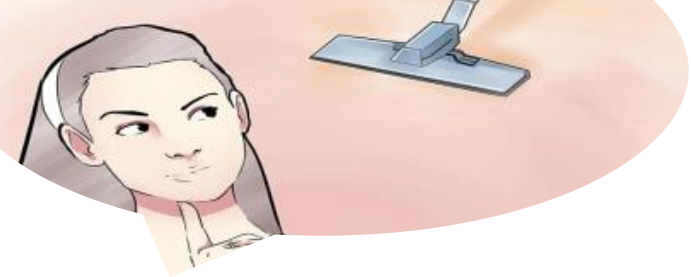

8. Imagine you are trying to hold back urine; lift and squeeze from the inside.

- $\quad$ Try and hold that action for the count of three.

- Imagine that you are trying to stop yourself from passing wind; lift and squeeze your anus and hold for a count of three.

- Combine those two movements into one fluid movement. Starting from the front, lift and squeeze, don't let go, follow through to your anus, lift and squeeze.

- Relax and hold this position for 10 seconds. Rest for 10 - 20 seconds and repeat.

- Work towards 12 strongholds and as it starts to

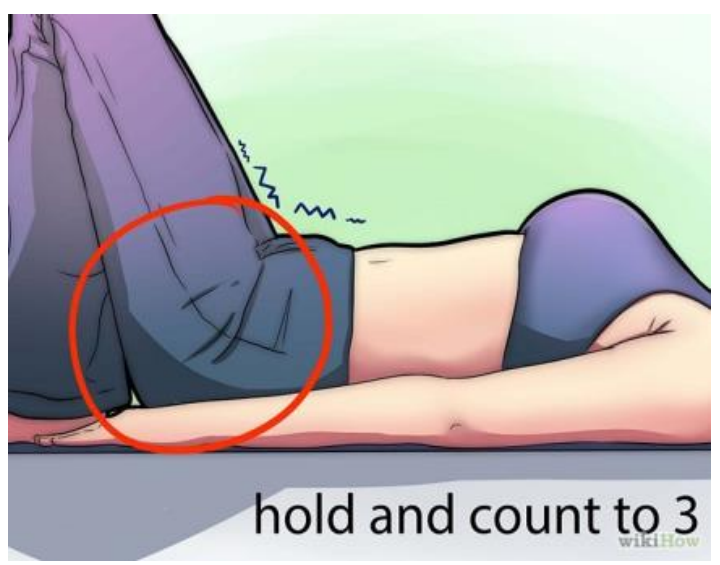

become easier, try holding for longer, and repeat as many times as you can.

\section{Ask for help if you don't think you're doing Kegel} properly.

- Your doctor can help you identify and isolate the correct muscles to perform the exercise.

- If necessary, your doctor can provide biofeedback training. This involves placing a monitoring device inside your vagina, and electrodes externally. The monitor can tell you how successful you were in contracting your pelvic floor muscles and how long you were able to hold the contraction.

- A doctor can also use electrical stimulation to help you identify the pelvic floor muscles. During this process, a small electrical current adheres to the pelvic floor muscles. When activated, the current automatically contract the muscle. After some use, you'll most likely be able to reproduce the effect on your own.

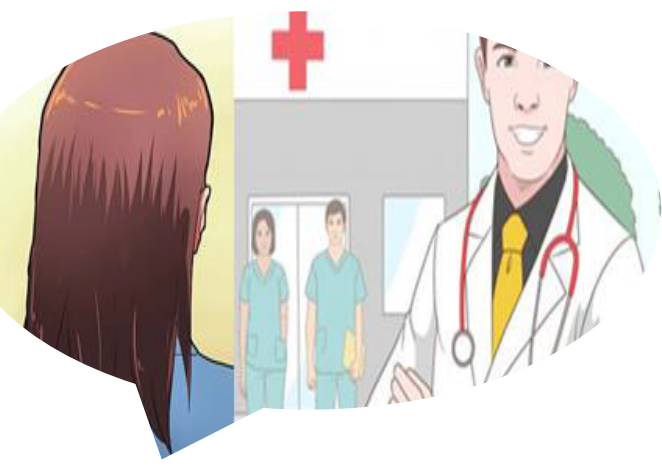

10. Perform Kegel exercises regularly, about 3 or 4 times a day.

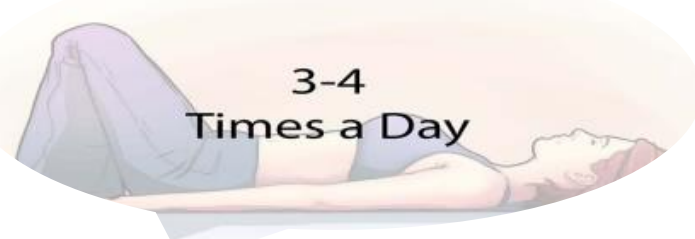

11. Expect results in a few months if you do Kegel regularly.

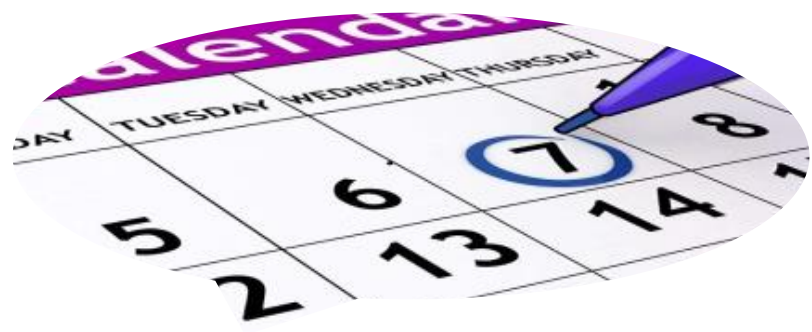


- $\quad$ For some women, the results are dramatic

- For others kegels prevent further urinary tract problems.

12. You can practice more complex Kegels after mastering the basics. Tighten up and down the vaginal barrel progressively.

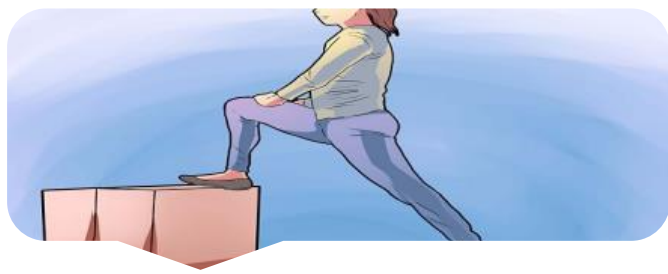

Tips

- $\quad$ Try not to hold your breath, squeeze your buttocks or thighs, pull your tummy in tightly, or push down instead of squeezing and lifting.

- $\quad$ You can perform slow and quick kegel exercises any time and no one will be aware of what you are doing. Some women find it easy to incorporate them into their routine while driving, reading, watching TV, talking on the phone, or sitting at a computer.

- As you become more confident with these exercises, you will find that you will be able to do them standing up. The important thing is to keep practicing throughout the day and you can do them while you're washing the dishes, waiting in a queue, or even sitting at your desk in the office, during television show commercials, or when you are stopped at a stoplight while driving.

- $\quad$ Pregnant women can perform Kegel exercises.

- Imagine your lungs are in pelvis and relax perineum on inhaling and draw upon exhale.

- $\quad$ Try to eat healthier foods too.

\section{Warnings}

- Always do Kegel with an empty bladder. Doing Kegel with a full bladder can weaken your pelvic floor and increases your risk of contracting a urinary tract infection.

- Don't do Kegels while using the bathroom, except to locate the muscles initially. Interrupting urine flow can result in urinary tract infections

\section{How often should I do them?}

Start doing Kegels a few at a time throughout the day. As your muscles start to feel stronger, gradually increase both the number of contractions you do each day and the length of time you hold each contraction, up to ten seconds. Do them in sets of ten and try to work up to three or four sets about three times a day.

Make Kegels part of your daily routine: For example, you could do a series when you wake up in the morning, another while you're watching TV, and then again before you go to bed. But it really doesn't matter when or where you do them as long as you do them regularly.

Be patient and keep at it. It may take three to six weeks of regular Kegels before you notice an improvement in bladder control.

\section{How long should I continue doing Kegels?}

Don't stop doing Kegels! You have to continue the exercise to maintain your strength and ward off incontinence as you age. So make doing Kegels a lifelong habit.

Working to keep your pelvic floor muscles strong may also help guard against pelvic organ prolapse, a common condition among older women. In pelvic organ prolapse, relaxation of the pelvic muscles and ligaments allows the uterus, bladder, and rectal tissue to sag and protrude into the vagina. This may cause incontinence, as well as other symptoms including a sense of pelvic heaviness, low back pain, and discomfort during sex.

\section{References}

1. Ashton-Miller JA, DeLancey JO. Functional anatomy of the female pelvic floor. Ann. N. Y. Acad. Sci. 2007; 1101: 266-296.

2. Zanetti MR, Castro Rde A, Rotta AL, Santos PD, Sartori M, Girão MJ. Impact of supervised physiotherapeutic pelvic floor exercises for treating female stress urinary incontinence. Sao Paulo Med J. 2007; 125(5): 265269.

3. KEGEL AH. Progressive resistance exercise in the functional restoration of the perineal muscles. Am. J. Obstet. Gynecol. 1948; 56(2): 238-248.

4. Kahyaoglu Sut H, Balkanli Kaplan P. Effect of pelvic floor muscle exercise on pelvic floor muscle activity and voiding functions during pregnancy and the postpartum period. Neurourol. Urodyn. 2016; 35(3): 417-422.

5. Dumoulin C, Cacciari LP, Hay-Smith EJC. Pelvic floor muscle training versus no treatment, or inactive control treatments, for urinary incontinence in women. Cochrane Database Syst Rev. 2018 04; 10: CD005654.

6. McLennan MT, Melick CF, Alten B, Young J, Hoehn MR. Patients knowledge of potential pelvic floor changes associated with pregnancy and delivery. Int Urogynecol J Pelvic Floor Dysfunct. 2006; 17(1): 22-26.

7. Cavkaytar S, Kokanali MK, Topcu HO, Aksakal OS, Doğanay M. Effect of home-based Kegel exercises on quality of life in women with stress and mixed urinary incontinence. J Obstet Gynaecol. 2015; 35(4): 407-410

8. Milsom I, Gyhagen M. The prevalence of urinary incontinence. Climacteric. 2019; 22(3): 217-222.

9. Bump RC, Hurt WG, Fantl JA, Wyman JF. Assessment of Kegel pelvic muscle exercise performance after brief verbal instruction. Am. J. Obstet. Gynecol. 1991; 165(2): 322-329. 
10. Ibrahim H., Elgzar W., Hassan H. Effect of Warm Compresses Versus Lubricated Massage during the Second Stage of Labor on Perineal Outcomes among Primiparous Women. IOSR Journal of Nursing and Health Science. 2017; 6(4): 64-76. doi:10.9790/1959-0604056476.

11. Braekken IH, Majida M, Engh ME, Bø K. Can pelvic floor muscle training reverse pelvic organ prolapse and reduce prolapse symptoms? An assessor-blinded, randomized, controlled trial. Am. J. Obstet. Gynecol. 2010; 203(2): 170.e1-7.

12. Marques A, Stothers L, Macnab A. The status of pelvic floor muscle training for women. Can Urol Assoc J. 2010; 4(6): 419-424.
13. Park SH, Kang CB, Jang SY, Kim BY. [Effect of Kegel exercise to prevent urinary and fecal incontinence in antenatal and postnatal women: systematic review]. J Korean Acad Nurs. 2013; 43(3): 420-430.

14. Smith FJ, Holman CD, Moorin RE, Tsokos N. Lifetime risk of undergoing surgery for pelvic organ prolapse. Obstet Gynecol. 2010; 116(5): 10961100 .

15. Chow D, Rodríguez LV. Epidemiology and prevalence of pelvic organ prolapse. Curr Opin Urol. 2013 Jul; 23(4): 293-298. 